\title{
ALIMENTAR-COMER: \\ SUBSTÂNCIAS SOCIÁVEIS E SUTIS NO REPASTO RITUAL DO \\ CANDOMBLÉ TERESINENSE
}

\author{
Fernanda da Silva Costa Soares ${ }^{1}$ \\ Celso de Brito ${ }^{2}$ \\ Potyguara Alencar dos Santos ${ }^{3}$
}

\section{Introdução}

"[...] 'eating' refers to many acts other than taking in food".

Marilyn STRATHERN,

In Eating (and Feeding) (2012: 6)

O argumento de conteúdo investigado e posto sob discussão no espaço deste artigo incide sobre a proposta de pensar a relação entre as qualidades sociáveis e sutis dos alimentos que circulam pela cena ritual-festiva da casa Ilê Asé Opásoró Fadaka, primeiro terreiro de candomblé da cidade de Teresina, Piauí.

Por substâncias alimentares (i.) "sociáveis" e (ii.) "sutis" são entendidos: primeiro, o potencial integrador de divindades e pessoas de uma confissão de culto religioso exercido pelos alimentos, principalmente quando eles possibilitam relações generalizadas entre essas partes, e, secundariamente, os contatos que suas substâncias sensíveis propiciam ao fazerem circular influências comuns à chamada "economia do axé" (Carvalho, 2011), que aglutinam as energias sensíveis e sutis dispostas ao derredor dos processos de arrecadação, processamento e distribuição dos alimentos que marcam seus regimes particulares de transformação.

Conduzidos pela descrição da Festa de Ogun, Oxossi e Osanyin, da casa Ilê Asé Opásoró Fadaka, intentamos pôr em hipótese o que se entende como sendo o movimento de elisão, no âmbito da experiência ritual do candomblé, entre dois gestos

\footnotetext{
${ }^{1}$ Universidade Federal do Piauí, Brasil. Email: fernanda.soares@ifpi.edu.br ORCID id: https://orcid.org/0000-0001-7550-7592

${ }^{2}$ Universidade Federal do Piauí, Brasil. Email: celsodebrito@yahoo.com.br ORCID id: https://orcid.org/0000-0002-3773-2104

${ }^{3}$ Universidade Federal do Piauí, Brasil. Email: potyguara.alencar@gmail.com ORCID id: https://orcid.org/0000-0002-9965-958X
} 

envolvidos com a vida social das comidas de santo: o "alimentar" (servir) e o "comer" (servir-se). Em síntese, o que aqui se dispõe em centro de consideração de um problema em franca investigação pelos pesquisadores é se, na execução da atividade ritual que envolve os alimentos sagrados, comer e alimentar (ou "alimentar os outros" e "alimentar-se") não se figurariam como atividades auto-referidas, isto é, de alguma forma elípticas: de modo que a todo momento da evolução da ritualística púbica suas ações são confundidas.

Chamamos tal processo de "elíptico" pelo caráter, sobretudo, incompleto que na experiência ritual parece significar os atos do "alimentar" e do "comer", isto se forem tratados apenas como etapas de significados isolados e hierarquizados entre si (Bechara, 2009) ${ }^{4}$. Como tentaremos fazer observar por meio da descrição de uma festa do terreiro Ilê Asé Opásoró Fadaka - e esteados pelo que argumenta Marilyn Strathern, em “Eating (and Feending)" (2012) -, os movimentos de "alimentar e comer" se parecem mais com dinâmicas não sucessivas, mutuamente influentes (ou implicadas) e não hierárquicas. Tais singularidades serão dissertadas posteriormente.

Adianta-se, porém, que no tropo da relação elíptica subjacente ao princípio do "alimentar-comer" há informado um processo em que, sempre que nos referimos que um "santo é alimentado pelos seus filhos", ou que "um filho de santo come da alimentação ritual do terreiro", ocultamos termos de valores simétricos: por trás de toda relação de alimentar um santo há um ato sutil de comer, assim como em todo movimento físico de comer o repasto ritual há subentendida uma ação de alimentar um “corpo que não é (de todo) seu” (coisa como propriedade sua, individualizante); já que a pessoa do candomblé é feita para o seu santo através do ori, sua "cabeça” (Hampaté Bâ, 1981). Comendo, o santo alimenta o corpo material da comunidade; se alimentando daquilo que o santo se serve - seja de forma substancial direta ou por influência sutil indireta -, a comunidade come da força da divindade, que é, ao mesmo tempo, física, indefectível e intangível.

\section{Regimes de transformação e alimentos rituais}

4 A noção de "elipse" que aqui ganha emprego tem inspiração na figura de linguagem comum à estilística da língua portuguesa, que trata da possibilidade de supressão de termos de uma frase sem necessariamente comprometer o entendimento da sua lógica argumentativa. Como lembra Bechara (2009:34), "na maioria dos casos reais da chamada elipse, o que se tem, na verdade, é uma forma de super ordenação (quase sempre combinada com uma substituição por retomada)". 
No seu célebre ensaio “Classificado como comestível”, Mary Douglas (1998) argumenta que os alimentos compõem, no espaço dos mundos inventados pelos humanos, aquele conjunto organizado de unidades que compatibilizam os "complexos processos de ordenamento para as suas vidas" (Douglas, 1998:77, nossa tradução). Com tal proposição, a autora visa fazer observar que as comidas são mais que substâncias conduzidas às nossas necessidades nutrizes, e que por isso podem estar investidas de funções classificatórias que sobrepõem valores não físicalistas a elas.

Quando pensamos na conversão ritual dos alimentos em "comidas de santo" dentro do candomblé, a proposição de Douglas parece aclarar ainda mais o seu sentido. Pois, no espaço da organização social promovida por essa comunidade de culto, onde quase tudo nos gestos ritualísticos dos seus adeptos inspira a existência de uma "grande boca" (Lody, 1998:23) que a tudo divide, ceia e transforma, os alimentos cumprem funções outras. Basicamente, manifestam-se com e a partir deles duas "ontologias políticas" (Stengers, 2018): uma operante ao nível das relações ônticas e pragmáticas entre os entes humanos, que interagem entre si pela socialização das comidas, seus preparos e seus repastos; e a outra por meio da aproximação entre o panteão e a ceia (que a ele cabe) e as pessoas, com suas técnicas de preparo, seus serviços e suas participações na reciprocidade dos alimentos. Dentro dessa ontologia política, a comida de santo generaliza as interações e simetriza as condutas, propiciando, substantiva e sutilmente, que "aquilo do que ceia o panteão, os homens também comam".

$\mathrm{Na}$ análise que encetamos a produzir, as comidas de santo tendem a ser pensadas para além do caráter essencialista incentivado pela etnologia afro-brasileira do início do século XX, assim também como não se acomodam nas interpretações dos afrobrasilianistas, que poderiam pensar essas unidades da cultura como elementos integrantes tão-somente de uma sócio-política inerente à vida dos terreiros (Banaggia, 2008). Para o víeis analítico ora em escolha, a "comida de santo" é tanto elemento comunicador de uma ontologia subjacente às vivências particulares com os alimentos e suas vitalidades de toda ordem, quanto inspira, de igual modo, uma política. Trata-se, como já dito antes, de compreender a ontologia política dessas substâncias em seus regimes de transformação, pensando a eficácia do que elas fazem demover dentro de um pluriverso relacional feito de entes humanos, substâncias vitais (como os próprios 

alimentos e suas forças sutis manifestadas pelo axé) e o panteão das divindades. Enfim, um pluriverso no sentido de essas unidades advirem de e unificarem

mundos heterogêneos que caminham juntos como uma ecologia política das práticas, negociando suas dificuldades em conviverem a partir dessa mesma heterogeneidade (De La Cadena; Blasser, 2018: 4, nossa tradução).

Como faz ressaltar Wanderson Flor do Nascimento, em "Alimentação socializante" (2015), o panteão e as pessoas do candomblé só se realizam enquanto unidades existentes material e relacionalmente na condução evocada pelos alimentos:

É importante notar que, para as sociedades tradicionais africanas, as
divindades compõem o tecido social da mesma maneira que as pessoas,
precisando também de se alimentarem e contribuírem para os ciclos que
promovem a possibilidade de que o alimento continue existindo para todo o
mundo.Como a ancestralidade é um princípio fundamental de grande parte
destas sociedades tradicionais, é comum que os ancestrais comam primeiro,
embora em conjunto com as outras pessoas (Nascimento, 2015:63-64).

Como ainda assinala Nascimento (2015:65), a experiência viva do terreiro é toda ela baseada em "manter a boca do mundo mastigando [...] pois sempre há o que comer", movimento através do qual a própria comida "distingue os seres e os colocam em relação" (Nascimento, 2015:66). No espectro mais amplo de produção da vida religiosa dentro da comunidade de culto, Miriam Rabelo acentua o caráter estético e ético envolvido nos regimes de transformação dos alimentos. As análises promovidas por tal pesquisadora, assim como a de outros antropólogos e pensadores adeptos da própria religião, como é o caso de Wanderson Flor do Nascimento e Luís Tomás Domingos (2011), tendem a centralizar a importância da vida alimentar no espaço integral de produção da vida religiosa para as denominações religiosas afrodescendentes:

\begin{abstract}
A presença conspícua da comida no terreiro aponta para a centralidade da transformação no candomblé. Atenção às atividades de preparo, distribuição e consumo do alimento permite-nos entender, além do mais, como a transformação cultivada no terreiro reveste-se de dimensões estéticas e éticas. Essas atividades mostram-nos, de fato, como ética e sensibilidade estão estreitamente imbricadas no candomblé (Rabelo, 2013:87).
\end{abstract}

Aliando a dimensão "substantiva" (nutriz) à "ética" (deontológica) para tratar dos alimentos, Sidney Mintz (2001:31) já chamava a atenção para o fato de que "nossos corpos são produtos, resultados do nosso caráter, que, por sua vez, é revelado pela maneira como nos alimentamos". Tal asserção faz distinguir um valor duplicado quando 
"Alimentar-Comer": Substâncias Sociáveis e Sutis no Repasto Ritual...

pensamos o alimento dentro das práticas comuns de um universo religioso como o candomblé, dentro da qual os atos prescritos - como aqueles do se alimentar e ser alimentado - e a hierarquia moral das práticas estruturam o conjunto dos regramentos éticos das condutas coletivas (Abimbola, 1971; Wiredu, 2010).

Para além da prova de que os alimentos e suas manipulações são centrais na conformação dos mundos da vida do candomblé - entendimento já há muito consolidado pelas etnografias dos ambientes de terreiro (Beltrame, 2008; Nadalini, 2009; Aguiar, 2012; Mascarin, 2013; Santos, 2018) -, ao que pretendemos chamar atenção focaliza, antes, a aparente univocidade existente entre dois gestos envolvidos com os alimentos rituais: o comer e o alimentar, a atitude dos corpos que buscam a comida e daqueles que são servidos por ela dentro da vida ritualizada.

No geral, tendemos a estender a concepção afirmada por Rabelo de que "no comer, a agência é distribuída entre o sujeito que come e a coisa comida" (Rabelo, 2013:93). Ao que discutiremos a partir do excerto etnográfico apresentado no espaço deste artigo, a agência triádica dos que são alimentados com prioridade (os orixás), dos que se alimentam em subsequente (a comunidade de culto) e da própria comida transformada instaura uma relação elíptica; isto é: de figuras verbais (comer-alimentar) que embora subnotificadas às relações, ainda expressam seus valores na força do que deixam subentender. Assim, quando se informa que "o santo é alimentado", fica subentendido que as pessoas do terreiro também estão a comer, desde que com o ato de alimentar o santo se reequilibra a força vital material e sutil da casa e das várias escalaridades relacionais existentes dentro dela. Da mesma forma, quando um membro da comunidade de culto informa que se serve do alimento sagrado, que o come em assembléia, subentende-se que com o ato a pessoa cede substância, força, vitalidade ao corpo que sustenta seu ori, a "cabeça" do ente orgânico e espiritual que pertence ao santo.

Em revisite do material etnográfico produzido a partir de vivências com grupos territorializados em meio à região cultural da Melanésia, Marilyn Strathern procura nos lembrar que o "comer" (eating) pode estar "envolvido com muitos outros atos que não apenas com a ingestão de alimentos; pela Melanésia, ele é um idioma para toda sorte de ações sociais”, cita a autora (Strathern, 2012:7, nossa tradução). Comparativamente, lembra do caráter de "operador lógico" que a ingestão de alimentos tem no contexto amazônico ameríndio, ao acompanhar o trabalho de Vilaça (2010). No entanto, é a confusão da agência sutil existente entre os atos de "comer" e "alimentar" aduzidos de 

suas próprias pesquisas que nos rende maior inspiração. Segundo ela, é preciso considerar a aplicação lógica (ou de sentido) e pragmática imanente à borradura entre o eating e ofeeding para alguns contextos analíticos explorados pelas nossas etnografias:

Eating is frequently put in relation to feeding. What perhaps takes the place of the constant Amazonian possibility of becoming prey (being eaten) is something closer to that other hazard: being put in a position of being fed, the risk of what eating opens one up to. It takes proper food from the right source to make feeding nourishing. (Whether giving food or consuming it, both transitive and intransitive senses of the English 'feeding' apply.) (Strathern, 2012:7)

Em sentido mais geral, o que se alimenta está sempre em relação direta com a materialidade da coisa que alimenta, havendo, por essa dupla abertura (ou rendição) constitutiva, uma momentânea subsunção das posições entre "sujeito" e "objeto" do ato nutritivo. Para o caso do candomblé, reproduzimos a observação de Rabelo (2013) que enfoca, antes, a importância do predicado da "transformação" na experiência ritualística da alimentação, deixando de lado as diferenças assimétricas entre o "ser alimentado" e o "alimentar":

No comer, poderíamos simplesmente dizer, destaca-se a transformação. Se recuarmos o olhar de modo a situar os eventos rituais em que comem os orixás, o ori e os adeptos humanos em um quadro um pouco mais amplo de atividades que envolvem desde o preparar a oferenda de comida até o recolher e dispor da oferenda feita, ou ainda, se deslocarmos nossa atenção, do ato de comer, para as comidas que são preparadas e ofertadas, encontramos a mesma visibilidade da transformação - tema fortemente acentuado no candomblé. Há uma vantagem especial no exercício deste recuo: permite-nos passar de uma discussão do ritual para uma reflexão acerca da dinâmica cotidiana do terreiro, ou melhor, de uma análise dos grandes eventos públicos para uma descrição dos pequenos ritos que pontuam o dia a dia (Rabelo, 2013:95).

Pensar o "comer" e o "alimentar" como atos recíprocos de circulação material e sutil de substâncias entre os atores de uma comunidade confessional de culto - os seus pais e filhos de santo, principalmente - e os seus orixás, é o que nos incentiva a compreender o repasto ritual por meio dos seus "regimes de transformação": que compreendemos como sendo o fluxo das influências entre agentes rituais que tornam os movimentos de alimentar e comer como que princípios não sucessivos ou subsequentes - já que podem ser pensados como coincidentes e não dispostos em etapas -, mutuamente influentes e, por isso mesmo, não hierarquizados; já que "alimentar" (servir) não é menos importante que "comer" (servir-se): todos fazem parte de um 
"Alimentar-Comer": Substâncias Sociáveis e Sutis no Repasto Ritual...

mesmo plano simétrico de influências que possibilitam que "do que ceia o panteão, coma também os homens". Mesmo que alguns alimentos sejam reservados apenas ao deleite especial dos orixás, entende-se que a substância sutil que eles revelam voltará a circular pela comunidade de culto através dos corpos duplamente fortalecidos dos seus filhos e pais de santo, fechando o ciclo da "economia do axé" dentro do corpo coletivo da casa e dentro dos corpos "individualizados" dos seus múltiplos membros.

O que o excerto etnográfico disposto a seguir procura passageiramente relevar é o ambiente geral em que essa circulação de substâncias sociáveis e sutis ocorre, também flagrando alguns movimentos por trás dos regimes de transformação dos alimentos. A descrição é fruto de incursão recentemente realizada pelos pesquisadores ao espaço da Festa de Ogun, Oxossi e Osanyin, propiciada pelo primeiro terreiro de candomblé da cidade de Teresina, Piauí, o Ilê Asé Opásoró Fadaka.

\section{Sobre a fundação e restauração da casa Ilê Asé Opásoró Fadaka}

A casa Ilê Asé Opásoró Fadaka, também conhecida como Cajado de Prata, foi fundada em 1985 pelo babalorixá Oscar de Oxalá, que "fez seu santo" em Salvador, na Casa Branca, Obatoni, e na casa de Jeje; as mais tradicionais da Bahia. Por isso, desde sua fundação, a casa mantém laços estreitos com a capital baiana e com seus terreiros. Localizada no bairro Pirajá, zona Norte de Teresina, é conhecida como a primeira casa de candomblé da cidade (Luz et al., 2013).

Em agosto de 2014, o babalorixá Oscar de Oxalá foi assassinado nas dependências do terreiro, deixando dito em vida que sua sucessora seria sua sobrinha, Edarlane Andrade, hoje conhecida como Edarlane de Ayrá. Após a morte do pai de santo, a casa interrompeu seu funcionamento por aproximadamente dois anos.

Edarlane, hoje com 27 anos, é considerada a mais jovem yalorixá do Piauí (Arrais, 2019). Com uma responsabilidade que já havia lhe sido apontada desde criança, ela precisou assumir precocemente a missão de ser uma líder religiosa de uma das mais tradicionais casas de candomblé do Piauí. Formada em Fisioterapia, ela diz não exercer a profissão devido às demandas do seu trabalho como líder religiosa.

Ainda muito nova, Edarlane frequentava o terreiro de candomblé do tio, que desde cedo percebeu sua notável evolução espiritual. De forma precoce, teve sua 
Fernanda da Silva Costa Soares, Celso de Brito \& Potyguara Alencar dos Santos primeira incorporação aos 12 anos, e seu orixá assentado com 13 anos, por obra de seu antecessor espiritual, o babalorixá Oscar de Oxalá; porém, sua definitiva iniciação ocorreu apenas em 2011, dois anos antes do assassinato do seu iniciador. Por ser muito jovem, e a iniciação requerer uma árdua reclusão, à época de estar hábil a assumir os trabalhos básicos da casa, seu tio pediu que ela priorizasse seus estudos colegiais.

Tais eventos do histórico de consolidação do terreiro chamaram a atenção dos pesquisadores para um aspecto, esse que acabou centralizando a problemática da proposta de pesquisa que começávamos a realizar ao final de 2018. Passamos a indagar sobre como as "comidas de santo", em seus regimes de transformação característicos, operavam como referenciais de restauração da existência física, social, afetiva, política e ritual da casa, anos após o assassinato do seu babalorixá fundador e da afirmação da liderança feminina da yalorixá Edarlande de Ayrá. É uma parte do acumulado da pesquisa resultante desse primeiro nível de problematização que exploraremos a seguir.

\section{Alimentando e comendo da Festa de Ogun, Oxossi e Osanyin}

A decoração do salão onde acontecem os rituais públicos (espaço chamado de "barracão") era predominantemente branca, com folhas espalhadas pelo chão, plantas e fitas afeitando o teto. No poste central, muitas frutas (coco verde, melancia, abacaxi, laranja, mamão, milho verde, uva, banana, tangerina), e, acima, uma travessa com o amalá de Xangô decorado com uvas. ${ }^{5}$

A cerimônia começou às $20 \mathrm{~h} 30$ com a apresentação dos filhos da casa e dos convidados; adeptos de outra casa, pai e filhos de santo, todos estavam dispostos na roda. Os espectadores ao chegarem ficavam ao redor do salão. A apresentação durou aproximadamente uma hora. Nela, as músicas eram cantadas em sequência a cada um dos orixás, enquanto os filhos dançavam ao redor do poste central. O ritmo e os passos de dança mudavam de acordo com o orixá. As músicas eram contagiantes, bem como a dança, que era guiada pelo comando da yalorixá Edarlande de Ayrá, a sucessora do babalorixá Oscar de Oxalá.

5 O evento ocorreu nas dependências da casa llê Asé Opásoró Fadaka, em 27 de abril de 2019. A equipe de pesquisadores teve sua visita gentilmente assentida pela yalorixá Edarlande de Ayrá, a quem dirigimos nossa gratidão. 
"Alimentar-Comer": Substâncias Sociáveis e Sutis no Repasto Ritual...

Em derredor, os atabaques sonorizam alto e as iaôs cantavam e dançavam três vezes para cada orixá. Começaram por Ogun, o "abridor de caminhos", terminando por Oxalá, o orixá-babá, o mais velho de todos. A função primeira da roda é a de invocar os orixás à presença dos seus cultuadores (Maia, 1985).

Nesse momento, algumas filhas da casa incorporaram os santos, "caíram no santo", sendo imediatamente auxiliadas pela yalorixá Edarlane e a kekerê Iara, que mudaram a arrumação das suas roupas e dos seus panos de cabeça. Logo depois da incorporação das cinco iaôs, elas foram retiradas para o interior da casa, local chamado de "camarinha", enquanto os filhos de santo e o babalorixá convidados se despediram da festa. A música seguiu tocando sem parar. No espaço da roda, trabalhadores da casa serviram refrigerantes, água e salgadinhos aos convidados. Havia também um bolo decorado com frutas e brigadeiros ao redor.

Após a "descida dos santos" em que a yalorixá e os filhos da casa se retiraram para o interior, entrou no salão uma das filhas de santo vestida de branco (não foi paramentada com as roupas e insígnias do seu orixá para que a festa não ficasse parada), Rombona de Yansã, junto com a yalorixá. Ambas começaram a dançar por cerca de uma hora; intervalo durante o qual as demais filhas de santo eram vestidas com as roupas, insígnias e armas de seus respectivos santos.

O momento seguinte foi de entrada dos orixás (Iemanjá, Ogun, Oxossi e Oxalá) paramentados e puxados pela yalorixá e a kekerê. Houve uma ação importante executada na entrada dos orixás no salão, evento que foi posteriormente explicado pela yalorixá: ele marcou o instante em que Iemanjá escolheu um dos filhos da casa para ser seu ogã , o que figurava como uma honra e um reconhecimento do orixá pelo trabalho prestado pelo filho no zelo da casa. O novo ogã sentou-se numa cadeira de honra e recebeu as felicitações dos trabalhadores. Após esse momento, a yalorixá organizou as danças individuais dos orixás; aqueles que não estavam dançando, ficavam sentados ao redor do poste.

A primeira apresentação foi de Ogun - orixá do "abre caminhos", a Iaô de Ogun Iara. Com sua a roupa azul escuro, com folhas de palmeira cruzadas, sua espada e seu escudo e um capacete de metal. A dança de Ogun foi efusiva, rápida e agressiva, em alguns momentos, mas sempre orientada pela yalorixá, que utilizava o adjá (pequena sineta) como forma de chamar atenção e guiar o orixá. O adjá é utilizado pela yalorixá durante toda a festa. Especificamente depois da descida dos orixás, seu uso é marcante, principalmente por ter a capacidade de trazer o orixá de volta aos limites do salão, 
Fernanda da Silva Costa Soares, Celso de Brito \& Potyguara Alencar dos Santos fazendo-o recuar da proximidade dos convidados e da saída do barracão. Em momentos diferentes, dois convidados incorporaram e foram retirados do salão para o interior da casa.

Percebeu-se que a primeira filha a dançar, Rombona de Yansã, estava sentada do outro lado do salão com atitudes que pareciam as de uma criança: em uma esteira sobre o chão, ela brincava com uma boneca. Após a subida do orixá, ela incorporou o erê (espírito, entidade protetora, que tomam conta dos filhos de santo).

Em dado momento da dança de Ogun, ele começa a levantar a barra da saia e a yalorixá anuncia que “Ogun quer um agrado!", dinheiro. Após esse momento, o orixá distribui a alguns participantes ramos de folha de palmeira. Em vários momentos, Ogun parava na frente de algumas pessoas (ou da casa ou dos convidados, adeptos ou não do candomblé) e fazia uma saudação, em seguida abraçando forte duas vezes. Sendo que nas apresentações seguintes dos orixás esse ato foi pouco frequente.

Finalizada a apresentação de Ogun, ele foi "sentado", enquanto Iemanjá era, por sua vez, apresentada. Com suas roupas em tons de azul claro e verde, sua indumentária era o abebé (espelho) em uma mão e o alfange (um tipo de espada) na outra. Sua dança é mais lenta e compassada, seus braços se movimentam com leveza, imitando o movimento das ondas. Nesse momento foram servidos mais salgados e os brigadeiros, bem como água e refrigerante.

Em seguida, levanta-se Oxalá (orixá da criação), orixá ancião. Curvado e apoiado em um cajado prateado, chamado de paxorô. Esse vinha acompanhado de perto pela mãe de santo. A música e os passos se tornaram mais lentos e cadenciados. As vestes de Oxalá eram completamente brancas, performando uma apresentação rápida. Nesse momento as trabalhadoras da casa começam a servir o jantar, composto pelas seguintes comidas de santo:

Quadro 01 - Repasto ritual e concepções substantivas e sutis das comidas de santo servidas na Festa de Ogun, Oxossi e Osanyin, da casa Ilê Asé Opásoró Fadaka.

$\begin{array}{ccc}\text { REPASTO } & \text { CONCEPÇÃO } & \text { ORIGEM E } \\ \text { RITUAL } & \text { SUBSTANTIVA } & \text { CONCEPÇÃO SUTIL } \\ & & \\ \text { Feijoada } & \text { Feijão preto, toucinho, } & \text { Oferenda }\end{array}$


"Alimentar-Comer": Substâncias Sociáveis e Sutis no Repasto Ritual...

\begin{tabular}{|c|c|c|}
\hline & $\begin{array}{l}\text { partes do porco, linguiça, } \\
\text { carne seca }\end{array}$ & a Ogun \\
\hline$E b \hat{o}$ & $\begin{array}{l}\text { Milho branco cozido } \\
\text { apenas em água }\end{array}$ & $\begin{array}{l}\text { Oferenda } \\
\text { a Oxalá }\end{array}$ \\
\hline $\begin{array}{l}\text { Amalá de azeite } \\
\text { de dendê }\end{array}$ & $\begin{array}{l}\text { Quiabo, cebola, azeite de } \\
\text { dendê e camarão seco }\end{array}$ & $\begin{array}{l}\text { Oferenda } \\
\text { a Xangô }\end{array}$ \\
\hline $\begin{array}{l}\text { Amalá de } \\
\text { azeite doce }\end{array}$ & $\begin{array}{l}\text { Quiabo, cebola, azeite } \\
\text { oliva e camarão seco }\end{array}$ & $\begin{array}{l}\text { Oferenda } \\
\text { a Ayrá }\end{array}$ \\
\hline Acaçá & $\begin{array}{l}\text { Milho branco ralado feito } \\
\text { mingau grosso e modelado }\end{array}$ & $\begin{array}{c}\text { Oferenda a } \\
\text { diversos orixás }\end{array}$ \\
\hline Acarajé & $\begin{array}{l}\text { Bolinho de feijão fradinho } \\
\text { frito em azeite de dendê }\end{array}$ & $\begin{array}{l}\text { Oferenda } \\
\text { a Iansã }\end{array}$ \\
\hline $\begin{array}{c}\text { Farofa de azeite de dendê } \\
\text { e camarão (padê) }\end{array}$ & $\begin{array}{l}\text { Farinha de mandioca, } \\
\text { azeite e camarão seco }\end{array}$ & $\begin{array}{l}\text { Oferenda } \\
\text { a Exu }\end{array}$ \\
\hline $\begin{array}{l}\text { Xinxim de } \\
\text { galinha }\end{array}$ & $\begin{array}{l}\text { Galinha em pedaços, } \\
\text { camarão seco, cebola e } \\
\text { azeite de dendê }\end{array}$ & $\begin{array}{l}\text { Oferenda } \\
\text { a Oxum }\end{array}$ \\
\hline Dibô & $\begin{array}{l}\text { Milho branco, cebola, } \\
\text { camarão seco e azeite de } \\
\text { dendê }\end{array}$ & $\begin{array}{l}\text { Oferenda } \\
\text { a Iemanjá }\end{array}$ \\
\hline Arroz & $\begin{array}{l}\text { Arroz cozido } \\
\text { sem tempero }\end{array}$ & $\begin{array}{l}\text { Oferenda } \\
\text { a Oxalá }\end{array}$ \\
\hline
\end{tabular}

Fonte: as informações dispostas em quadro foram registradas em notas de diário de campo e subsequentemente complementadas a partir de relatos colhidos junto aos membros da casa Ilê Asé Opásoró Fadaka, em 27 de abril de 2019.

Tais comidas foram postas em diante e servidas indistintamente a todos os convidados. Em termos sensoriais, em suas cores e formas características, as comidas eram, de um modo geral, neutras (tirante a feijoada), além de insossas, como preceitua a técnica culinária das comidas de santo.

Naquela noite, o último orixá a se apresentar foi Oxóssi, com sua roupa azul clara, seu arco e flecha, capacete de couro na cabeça e dois espanadores nas mãos. Sua dança foi mais rápida e graciosa, imitando sempre uma pontaria com os dedos. Os 

atabaques soaram ruidosos, bem como as músicas versificadas. No seu ato, o santo saudou alguns filhos e participantes, mas não muitos.

A essa altura, apesar de todo vigor e juventude da yalorixá, ela já manifestava sinais visíveis de cansaço. Em determinado momento, jogou vários feijões nos presentes e depois deu a cada pessoa um punhado, representando a fartura. A cerimônia se encaminhava para o final quando Oxossi pediu mais música.

Por fim, os orixás saíram do salão e a yalorixá agradeceu a presença de todos, falou do empenho da casa para a realização da festa e também da importância do candomblé e do axé na religião, discursando sobre como o candomblé se afirmava como uma forma de expressão cultural rica e necessária. Após sua fala, despediu-se. Mas não sem antes convidar a todos a se servirem das comidas de santo que estavam postas em uma mesa ao lado do salão, as mesmas que foram servidas durante a festa; elas foram postas ali em caso de alguém querer se servir de mais.

As pessoas foram saindo aos poucos, e a yalorixá permaneceu para receber os cumprimentos dos convidados. Após a festa, em conversa com ela, agradecemos pelo convite. Ela então nos mostrou as oferendas, como a comida de Xangô que estava no poste central: uma travessa de barro com uvas e o amalá. Nesse instante, a yalorixá falou mais uma vez sobre a "cultura das comidas do candomblé", os preconceitos que o povo de santo sofre e sobre a fundação do terreiro pelo seu tio e iniciador, o babalorixá Oscar de Oxalá. Ela falava com muito orgulho sobre a tradição de sua casa, por ser o primeiro terreiro de candomblé de Teresina. As demais casas da cidade trabalham com o candomblé e com a umbanda, cultos muito diferentes, segundo sua visão. Falou também sobre as suas dificuldades na condução da casa, por ser tão jovem e ter que renunciar ao convívio de sua família para cuidar dos seus santos, visto que ela residia em período integral no terreiro.

As filhas de santo que participaram da festa eram bem jovens, enquanto as pessoas que faziam o serviço das comidas durante a festa aparentavam mais velhas. Apenas a kekerê Iara e a equede Socorro eram anciãs.

Após os atos principais da noite, os filhos e filhas de santo da casa, dessa vez como erês, voltaram para o salão em grande algazarra, brincando e rolando no chão, ao que foram repreendidos pela kekerê Iara (mãe da yalorixá). A yalorixá chamou então os erês e filhos da casa que ainda estavam presentes para o "corte do bolo". Eles fizeram um círculo ao redor do bolo e entoaram uma canção em iorubá, seguido do corte pela yalorixá, que distribuiu porções entre os presentes. 
"Alimentar-Comer": Substâncias Sociáveis e Sutis no Repasto Ritual...

Oferendas do "pé do santo" foram arriadas antes da festa: para Oxossi, axoxô (milho amarelo cozido), para Osanyin, fumo e farofa, para Ogun, inhame assado. Oferendas como aquelas fazem parte do segredo ritual da casa; dessas, a yalorixá citou apenas alguns elementos envolvidos nos seus arranjos, embora ele seja composto de muitos outros.

\section{Sobre substâncias sociáveis e sutis}

Os eventos sequencialmente acima relatos contam de uma reunião concentrada de caráter público que acontecia alguns anos após o desfecho trágico da morte do babalorixá Oscar de Oxalá. As comidas preparadas e dispostas naquele momento eram, por essa razão, elementos colocados à apreciação e deleite dos convivas, à socialização de pessoas que fortaleceriam as redes de relações sociais e políticas da casa nos próximos anos. Desse modo, tais alimentos tinham seus predicados socializantes redobrados, já que cumpriam a função de renovar a vida do terreiro e das suas pessoas, restaurando antigos vínculos da casa e inaugurando outras.

Como demonstravam as sucessões de evoluções de danças e apresentações de divindades, a comida pontua os momentos em que se criam intervalos necessários entre esses vários movimentos: ora ela restaura as forças dos corpos, ora dá abertura à entrada de um novo santo, ora, ainda, informa da mudança das intensidades das interações rituais. Suas cores e formas, bem como o modo como foram preparadas e expostas, também insinuam as predileções dos próprios orixás, o complexo "ordenamento classificatório" imposto pelos alimentos que diz das interdições e das possibilidades de aproximações das origens das texturas (Douglas, 1998).

O protagonismo dos alimentos nesse espetáculo em que se abre uma "grande boca" pública em diante da generosidade da casa em restauração (Lody, 1998), revelase pela sua capacidade de burilar os ritmos, bem como abrir e fechar instantes dentre o conjunto das transformações que acontecem em termos das pessoas e dos seus movimentos coletivos e individuais. Por isso, em reprodução do que nos lembra Rabelo:

Pode-se dizer que o candomblé não apenas ressalta e cultiva a transformação - fato bastante visível na centralidade que assumem, nesta religião, atividades relacionadas à comida - mas que no terreiro cultiva-se a atenção e a 
sensibilidade às várias e diferentes (às vezes bastante pequenas) durações em que os materiais (e as pessoas) se transformam (Rabelo, 2013:97).

É do íntimo dessas durações que os regimes de transformação que fazem interagir pessoas, divindades e alimentos acontecem. São entre esses instantes que se simetrizam os valores comums da economia do axé, essa que circula, prioritariamente, através dos alimentos produzidos, oferecidos e consumidos. Nesse movimento mais geral, comer e alimentar já não se individualizam enquanto condutas: as forças sutis que se imantam a esses gestos, agora são transferidas às comidas e dessas aos santos e à comunidade de culto. Na festa do terreiro Ilê Asé Opásoró Fadaka, como apreciado pela descrição, as comidas são quase que indistintamente repartidas entre os santos e os convivas; o intento imanente a essa ação generosa, como devem ser todas os atos dadivosos (Mauss, 1974; Anspach, 2002; Lanna, 2000), é informar que naquela casa continuam a se reproduzir os gestos fundantes da tradição. E é a vitalidade das comidas que informa a todos que algo ainda vive e faz perdurar sua força naquele terreiro, apesar dos anos de insegurança quanto a um futuro.

\section{Conclusão}

Os dados ora movimentados constituem um conjunto de apurados de pesquisa em atual processo de sistematização dos seus resultados. São, dessa forma, tentativos os investimentos interpretativos acima produzidos. Reforçamos, em diante do exposto, que uma outra abordagem sobre o universo produtivo e ritual das transformações dos alimentos em comidas de santo precisa ser realizada.

No geral, as comidas rituais são tratadas como objetos da cultura material originariamente atreladas ao universo religioso, das quais são narradas apenas aquilo que no quadro acima foram chamadas de "concepções substantivas" e "concepções sutis" (Beltrame, 2008; Nadalini, 2009). Diferente dessas leituras finais das dinâmicas de transformação dos alimentos em comidas de santo, o que tentamos produzir foi uma abordagem que procurasse dar conta também dos agenciamentos simétricos que relacionamos princípios do "comer" (servir-se) e do "alimentar" (servir), discutindo a possibilidade de uma elisão dos sentidos desses gestos quando pessoas, entidades e 
alimentos se tornam interagentes e producentes de uma mesma ontologia política das trocas de substâncias sociáveis e sutis.

O avanço que antevemos na direção de uma nova leitura desses dados nos assinala a necessidade de pensar as figuras de movimento inerentes a esse pluriverso feito de humanos, divindades e materiais, pensando como essas substâncias duplamente qualificadas - "sociáveis" (unidades materiais que propiciam contatos generalizados entre entes da cena ritual) e "sutis" (unidades que portam influências em forma de valores não tangíveis, a exemplo do axé) - transitam, se transformam e modificam relações dentre as ações de arrecadação, processamento e distribuição dos alimentos.

\section{REFERÊNCIAS}

ABIMBOLA, Wande. “A concepção iourubá da personalidade humana” [Tradução, notas e comentário: Luiz L. Marins]. Colóquio Internacional para A Noção de Pessoa na África Negra. Paris: Centre National de La Recherche Scientifique, n. ${ }^{\circ}$ 544, 1971: 1-21.

AGUIAR, Janaina Couvo Teixeira Maia de. "Cadê meu ajeum?" A comida e seus vários significados nos terreiros de candomblé de Aracaju. I Seminário sobre Alimentos e Manifestações Culturais Tradicionais. Universidade Federal da Bahia, 2012: 1-15.

ANSPACH, Mark Rogin. À charge de revanche: figures élémentaires de laréciprocité. Paris: Éditions Du Sul, 2002.

ARRAIS, Lucrécio. Edarlane de Ayrá: a yalorixá (mãe de santo) mais jovem do Piauí.Jornal Meio Norte, Teresina/PI, 09 mar. 2019. Acessado em: 02 jul. 2019. Disponível em: https://www.meionorte.com/noticias/edarlane-de-ayra-a-iyalorixamae-de-santo-mais-jovem-do-piaui-357109.

BANAGGIA, Gabriel. Inovações e controvérsias na antropologia das religiões afrobrasileiras. Tese de Doutorado - Programa de Pós-Graduação em Antropologia 
Fernanda da Silva Costa Soares, Celso de Brito \& Potyguara Alencar dos Santos

Social da Universidade Federal do Rio de Janeiro (UFRJ/MN), Rio de Janeiro, 2008.

BECHARA, Evanildo. Moderna gramática portuguesa. Rio de Janeiro: Editora Nova Fronteira/Editora Lucerna, 2009.

BELTRAME, Ideraldo Luiz; MORANDO. Marsal. "O sagrado na cultura gastronômica do Candomblé”. In Antropologia e saúde. 2008, v. 05, n. ${ }^{\circ} 26$, p. 242248.

CARVALHO, José Jorge de. “A economia do axé: os terreiros de matriz afro-brasileira como fonte de segurança alimentar e rede de circuitos econômicos e comunitários”. In ARANTES, Luana Lazzeri; RODRIGUES, Monica (orgs.). Alimento: direito sagrado. Pesquisa socioeconômica e cultural de Povos e Comunidades Tradicionais de Terreiros. Brasília: MDS, 2011, p. 37-62.

DOMINGOS, Luis Tomás. "Visão africana em relação à natureza". In Anais do III Encontro Nacional da Associação Nacional de História ANPUH - GT história das religiões e das religiosidades. In Revista Brasileira de História das Religiões. Maringá (PR) v. III, n.9, jan/2011, p. 1-16.

DOUGLAS, Mary. "Clasificado como comestible". In Estilos de pensar. Barcelona: Gedisa Editorial, 1998, p. 153-166.

HAMPATÉ BÂ, Amadou. “A noção de pessoa na África Negra” [Tradução: Luiza Silva Porto Ramos e Kelvlin Ferreira Medeiros]. HAMPÂTÉ BÂ, Amadou. "La notion de personneen Afrique Noire". In: DIETERLEN, Germaine (ed.). La notion de personneen Afrique Noire. Paris: CNRS, 1981, p. 181-192.

LA CADENA, Marisol de; BLASER, Mario. A world of many worlds. Durham e London: Duke University Press, 2018.

LANNA, Marcos. Nota sobre Marcel Mauss e o ensaio sobre a dádiva. Rev. Sociol. Polit. 2000, n. 14, pp.173-194. 
LODY, Raul. Santo também come. Rio de Janeiro:Pallas, 1998.

LUZ, Lila Cristina Xavier Luz; SILVA, Vânia Reis Valéria; CAVALCANTE, Francisca Verônica. A condição juvenil em Teresina. Teresina: EDUFPI, 2013.

MASCARIN, Tereza de Fatima. Comidas de orixás: aspectos relevantes que fazem parte do cotidiano no terreiro de candomblé. In Anais do IV Encontro Nacional do GT História das Religiões e das Religiosidades - ANPUH-Memória e Narrativas nas Religiões e nas Religiosidades. Revista Brasileira de História das Religiões. Maringá (PR), V, n.15, jan/2013, p. 1-20.

MAIA, Vasconcelos. A B C do candomblé. São Paulo: GRD, 1985.

MAUSS, Marcel [1923-24]. Ensaio sobre a dádiva. Forma e razão da troca nas sociedades arcaicas. In : . Sociologia e Antropologia. v. II. São Paulo: Edusp, 1974.

MINTZ, Sidney. Comida e antropologia: uma breve revisão. $R B C S$, v. 16, n. 47, p. 3141, 2001.

NADALINI, A. P. Comida de santo na cozinha dos homens: um estudo da ponte entre alimentação e religião.Universidade Federal do Paraná, 2009.

NASCIMENTO, Wanderson Flor do. Alimentação socializante: notas acerca da experiência do pensamento tradicional africano. Revista Das Questões, v. 2, p. 6274, 2015.

RABELO, Miriam C. M. Rabelo. Os percursos da comida no candomblé de Salvador. Papeles de Trabajo, Año 7, n. 11, mayo de 2013, pp. 86-108.

SANTOS, Rafael Camaratta. A circulação do Axé através do movimento da comida: uma etnografia em um terreiro de candomblé da Bahia. Dissertação (Mestrado em Sociologia - UFRJ), Rio de Janeiro, 2018. 
Fernanda da Silva Costa Soares, Celso de Brito \& Potyguara Alencar dos Santos STENGERS, Isabelle. "The challenge of ontological politics". In. LA CADENA, Marisol de; BLASER, Mario. A world of many worlds. Durham e London: Duke University Press, 2018, p. 83-11.

STRATHERN, Marilyn. Eating (and feeding). The Cambridge Journal of Anthropology, v. 30, n. 2, p. 1-14, 2012.

VILAÇA, Aparecida. Strange enemies: indigenous agency and scenes of encounters in Amazonia. Durham: Duke University Press, 2010.

WIREDU, Kwasi. "African religions from a philosophical point of view". In TALIAFERRO, Charles; DRAPER, Paul; QUINN, Philip L. (eds.). A companion to philosophy of religion. Malden; Oxford; West Sussex: Blackwell, 2010, p. 3443.

Recebido 17/10/2019

Aprovado 11/12/2019 